\title{
O CÉU ESTÁ CAINDO: MÚSICA, DRAMA E IMAGINAÇÃO
}

The sky is falling: music, drama and imagination

\author{
TERESA MATEIRO \\ Universidade do Estado de Santa Catarina \\ teresa.mateiro@udesc.br \\ SILANI PEDROLLO \\ Universidade do Estado de Santa Catarina \\ profsilani@hotmail.com
}

\begin{abstract}
Resumo: Este artigo apresenta uma experiência de estágio realizada na educação infantil, integrando música e teatro. A metodologia de ensino adotada foi o drama na educação, abrangendo três elementos: musicalidade, corporeidade e plasticidade, com a temática exploração sonora vocal. As atividades musicais desenvolvidas foram apreciação e performance, desenhos sonoros e criação sonora. Foram escritos relatórios semanais, descritivos e reflexivos sobre o processo de atuação dos licenciandos, e as aulas foram gravadas em áudio e vídeo. Esse material, somado aos planos de aula e projeto de estágio, foi organizado em um portfólio digital. Ideias e propostas de autores das áreas de educação musical infantil, teatro educação e formação docente fundamentaram a reflexão e a discussão, principalmente sobre criação musical, drama, educação infantil, interdisciplinaridade e estágio curricular. Frente aos desafios encontrados, destaca-se a necessidade de fortalecer os conhecimentos para a formação profissional em música para atuar na educação infantil.
\end{abstract}

Palavras-chave: Criação musical. Estágio curricular supervisionado. Educação infantil.

\begin{abstract}
This article presents an experience of an internship in early childhood education integrating music and theater. The adopted teaching and learning methodology was process drama, covering three elements: musicality, corporeity and plasticity, under the theme of vocal sound exploration. The musical activities developed were appreciation and performance, sound drawings and musical sound creation. Weekly, descriptive and reflective reports were written about the process of the actions of the student music teachers, and the lessons were recorded in audio and video. The material, added to the lesson plans and internship project, was organized into a digital portfolio. Ideas and proposals from authors of the areas of children's musical education, theater education and teacher training were the basis of the reflection and the discussion, mainly concerning musical creation, drama, children's education, interdisciplinarity and curricular internship. The challenges that was found, reveals the necessity to strengthen the professional education in music about how to work with children's musical education.
\end{abstract}

Keywords: Musical creation. Interdisciplinarity. Music teacher education. 


\section{INTRODUÇÃO}

Naquele tempo antes de tudo, quando os animais ainda falavam, as árvores ainda sussurravam e quando havia apenas uma grande tribo (onde todos se amavam na mesma língua) [...] naquele tempo, o céu era dessa altura. Talvez um pouco mais alto, da altura de uma criança (Conto, Ulisses Belleigoli).

Imaginariamente, o céu estava baixando na Tribo Tchanan, os adultos andavam curvados, os pássaros não voavam mais, e as crianças, tendo que guiar os adultos, já não brincavam mais. Uma criança, mensageira dessa tribo, encontrou uma escola, com crianças da sua idade, na Universidade Federal de Santa Catarina (UFSC), que se chama Núcleo de Desenvolvimento Infantil (NDI), e resolveu pedir ajuda. Quatro turmas aceitaram o desafio e, unidas pelo mesmo problema, decidiram somar forças para empurrar o céu de volta. Por meio de um enredo ficcional, crianças de diferentes idades compartilharam ideias, estabelecendo conexões com o mundo e aprofundando suas experiências, singulares e coletivas.

Inicialmente, foi trabalhado o conceito de tribo em cada uma das turmas, no sentido de grupos de pessoas que se unem por um interesse comum ciclistas, bailarinos, cavaleiros, estudantes. Essa dinâmica é bastante adotada na pedagogia do teatro. Vidor (2010), ao trabalhar com professores de artes e licenciandos, dividiu-os em quatro grupos e denominou-os de tribos "para fazer uma conexão com a atualidade, em que os jovens se juntam por determinadas afinidades" (p. 52-53). A partir disso, cada turma escolheu um nome: Tribo Guerreiros Filhos de Urucum, Tribo Vagalume, Tribo do Piolho e Tribo das Estrelas. Estudantes estagiários dos cursos de Licenciatura em Música e Teatro estavam distribuídos em duplas nos quatro grupos. Ao longo de oito semanas durante o primeiro semestre de 2017, as tribos desenvolveram atividades com um único propósito: ajudar a Tribo Tchanan.

Este artigo tem como principal objetivo apresentar como licenciandos em música ultrapassaram as barreiras disciplinares desenvolvendo um projeto integrado com teatro, durante o período de estágio curricular supervisionado, com uma turma de educação infantil ${ }^{1}$. Ademais, como objetivos específicos, buscou-se: descrever e analisar o processo de ensino e aprendizagem desenvolvido a partir da exploração sonora vocal, tendo o drama como método de ensino, e investigar como a vivência dos processos interdisciplinares e a elaboração do portfólio digital contribuíram para o desenvolvimento reflexivo e autoformativo do estudante em formação docente.

\footnotetext{
1 Este trabalho integra o Projeto de Pesquisa "Da sala de aula à profissão: o uso de tecnologias móveis", desenvolvido no Grupo de Pesquisa Educação Musical e Formação Docente, coordenado pela Profa Dra Teresa Mateiro e com apoio de bolsa de iniciação científica da UDESC (PROBIC).
} 
Dessa forma, o foco será o trabalho desenvolvido na Tribo do Piolho, onde, além da professora regente, participaram ativamente uma estagiária e um estudante, bolsista de iniciação científica, ambos do curso de Licenciatura em Música. Esse grupo era composto por catorze crianças, sendo nove meninas e cinco meninos, entre os quatro anos e os quatro anos e onze meses. É importante destacar que essa Tribo fez parceria com a Tribo Guerreiros Filhos de Urucum - com o mesmo número de crianças, mas com faixa etária entre os três anos e os três anos e onze meses - para, conjuntamente, desenvolverem ações interdisciplinares, pois lá havia duas estagiárias de teatro.

As aulas da Tribo do Piolho, com duração de três horas por semana, foram filmadas e gravadas em áudio, assim como outras atividades com as demais tribos. Outrossim, foram escritos relatórios semanais, descritivos e reflexivos, sobre os processos de ensino e de aprendizagem. Esse material, somado aos planos de aula e projeto de estágio, entre outros, foi organizado em um portfólio digital. Para fins de pesquisa, os responsáveis pelas crianças dessas duas tribos assinaram um documento de autorização, assim como a coordenação da escola. Este estudo integra um projeto de pesquisa mais amplo, aprovado pelo Comitê de Ética da Universidade sob o parecer de número 1.328.698.

\section{NAS TRILHAS DO IMAGINÁRIO}

A situação-problema foi lançada para o grupo de crianças por meio de um pacote de alguns estímulos: fotos de crianças distantes, uma fita K7, pó mágico, bambu, desenhos e uma carta. Na pedagogia do teatro, esse pacote de estimulos, denominado de pacote composto por compreender vários artefatos, é um recurso pedagógico no processo criativo do Drama. Segundo Cabral (2006), os estímulos sugerem ações e motivações humanas para a construção de uma história, acrescentando novas informações à situação dramática.

As fotos eram das crianças da Tribo Tchanan que viviam longe, lá onde o céu estava caindo. A fita K7 continha informações sobre a situação da tribo, e as crianças precisavam descobrir o que era esse objeto, uma vez que não estava mais em uso. Depois, deveriam pensar em como fazer para ouvi-lo, pois há poucos aparelhos capazes de reproduzir essa fita. O pó mágico tinha a função de ativar a criatividade das crianças para buscar soluções aos problemas apresentados. O pedaço de bambu, por ser uma das únicas plantas que ainda resistiam na Tribo Tchanan, representava força, pois o bambu enverga com o peso, mas não quebra facilmente. Os desenhos de paisagens, como se fossem fotos, insinuavam que o céu estava baixando. A carta enviada pela Tribo Tchanan foi lida em tom de contação de história e informações foram dadas para os pequenos ficarem livres para continuar explorando e imaginando. 
Essa situação de faz de conta, segundo Teixeira (2005), é uma das principais atividades culturais em que as crianças reconstroem os significados, pois brincando elas operam no mundo diretamente disponivel e perceptível, transcendendo as demandas do aqui e do agora. A autora constatou que a prática do faz de conta em instituições de educação infantil é vista ora como recurso pedagógico para a aprendizagem de conteúdos escolares, ora como atividade de entretenimento ou recreação. A possibilidade de atuar em um mundo imaginário vinculado à presença de regras, onde situações, objetos e ações ganham novos significados, permite que a criança desenvolva "importantes funções psicológicas, como a memória, a ação voluntária, o pensamento abstrato, a afetividade e a imaginação" (Teixeira, 2005, p. 69).

$\mathrm{Na}$ área da pedagogia do teatro, a brincadeira do faz de conta está inserida na metodologia do drama, introduzida no Brasil por Beatriz Cabral ${ }^{2}$ na década de 1990. De acordo com Vidor (2010), é uma metodologia inglesa que se tornou conhecida como drama, drama na educação ou process drama. A autora explica que a presença de um conflito relacionado a um tema é o que "dá o mote para a construção da história e, consequentemente, para a escolha das estratégias que serão utilizadas" (Vidor, 2010, p. 29). O aluno amplia sua percepção de mundo quando mergulhado em um contexto ficcional que tenha alguma ressonância com a realidade e se identifica com papéis, ora representando um personagem ou narrando algum acontecimento, ora como ele próprio diante da situação apresentada.

A brincadeira e as interações são os eixos norteadores das práticas pedagógicas que compõem a proposta curricular da educação infantil, conforme a Resolução $\mathrm{n}^{\circ} 5$, que define as Diretrizes Curriculares Nacionais (Brasil, 2009, Art. $9^{\circ}$ ). Essas práticas devem garantir experiências que promovam: o conhecimento de si e do mundo; vivências éticas e estéticas; a curiosidade, a exploração e o encantamento; a imersão em diferentes linguagens; a interação com música e outras artes; entre outras (Brasil, 2009; DCNEI, 2010).

Aspectos próprios da linguagem teatral, como o contexto da ficção, os papéis assumidos pelo professor, a interação, a imitação e a expressão corporal, e as atividades musicais de apreciação, performance, explorações sonoras vocais e corporais, registros não convencionais e de criação sonora vocal coletiva permearam os encontros da Tribo do Piolho. O fio condutor foi o conto de tradição oral "A invenção das estrelas", recontado por Ulisses Belleigoli. A professora do grupo e os licenciandos de Música e Teatro, durante o semestre, assumiram diferentes papéis e viveram personagens em um ambiente de interação lúdica e experimentação dramática.

\footnotetext{
2 Professora aposentada do Departamento de Artes Cênicas e do Programa de Pós-Graduação em Teatro da UDESC.
} 
Nas escolas brasileiras, a metodologia do drama está sendo utilizada nas aulas de teatro, e o professor assume um personagem que, conforme esclarece Vidor (2010, p. 47), "dá ênfase à caracterização, cria um discurso condizente com as circunstâncias do personagem em termos de época, nacionalidade, ideologia, criando assim uma individualidade, enunciando o texto literal de um autor seja ele dramático ou não". Quatro personagens foram assumidos pelos estagiários e apresentados aos pequenos: dois à Tribo do Piolho Teobacia, a Encantadora de Crianças Cantantes e Clodoaldo, Apojatura da Costura Torta; e dois à Tribo Guerreiros Filhos de Urucum - Teobaldo, o Encantador de Crianças Dançantes e Filha de Urucum.

Os personagens trabalharam com atividades direcionadas às suas turmas, porém transitaram de forma interdisciplinar nos dois grupos. A ideia era que as quatro turmas criassem uma identidade para as suas tribos e que buscassem, por meio dos estímulos trazidos pelos personagens assumidos, uma solução para compartilhar com as outras tribos, unindo forças para, assim, cumprir o propósito de ajudar a Tribo Tchanan. Diferentes situações de interação pautadas pelo diálogo e respeito mútuo foram vividas pelas crianças, que discutiam alternativas de solução para o problema posto. Proporcionar momentos relacionados a habilidades para resolver problemas relacionais, buscando compreender a posição e o sentimento do outro, é uma das sugestões do BNCC (2017) para o currículo da educação infantil. E foi isso o que aconteceu. Cada tribo criou suas estratégias a partir do seu conhecimento e de sua experiência com o mundo real para dar subsídios ao mundo imaginário, pois eles precisavam enfrentar o céu que estava caindo.

A Tribo Vagalume trabalhou para abrir os portais e chegar à Tribo Tchanan. A Tribo das Estrelas encontrou nos animais coragem, cordialidade, elegância, agilidade e formas de locomoção, já que o céu estava tão baixo. As Tribos do Piolho e Filhos de Urucum trabalharam para alegrar o céu com música e dança, pois as crianças achavam que o céu estava triste. Antes do grande dia, o de ir até a terra da Tribo Tchanan, as quatro turmas se encontraram para compartilhar soluções em um encontro chamado de Conferência das Tribos. Toda essa experiência dramática, aliada a três elementos - musicalidade, plasticidade e corporeidade -, foi a metodologia de ensino adotada pelos estagiários de Música e Teatro.

\section{MUSICALIDADE, CORPOREIDADE E PLASTICIDADE}

A musicalidade foi desenvolvida por meio de elementos musicais que serviram de base para a criação sonora. As crianças ouviram áudios e assistiram a videos com sonoridades vocais diferentes das convencionais, como, por exemplo, as músicas do Grupo Barbatuques, que exploram as inúmeras possibilidades de extrair sons do corpo, e algumas canções do compositor Hélio Ziskind, que mesclam melodias e sonoridades não convencionais produzidos pela voz e pelo corpo. A partir dessas apreciações, as crianças foram convidadas a explorar seus próprios sons vocais e 
corporais, além de imitar outros sons produzidos pelos colegas. Depois, registraram esses sons em uma partitura analógica, isto é, em forma de "garatujas sonoras", conforme terminologia usada por Brito (2003). Esses registros gráficos representam a impressão subjetiva, a sensação e a percepção do gesto sonoro, revelando o modo como as crianças percebem e fazem relação com os eventos sonoros.

No decorrer do processo, a Tribo do Piolho recebeu a primeira visita, Teobacia, que esperava as crianças no bosque da escola. Ela contou que recebeu um pedido de ajuda da Tribo Tchanan e que resolveu pegar seu violão e sair à procura de novos sons e melodias com o intuito de alegrar o céu. Ficou sabendo que no NDI havia uma tribo, a do Piolho, que brincava de inventar sons. Então, propôs uma harmonia e uma melodia a partir da pergunta "Qual é o som da Luiza?". O nome da criança que produzia o som era cantado ao final da frase, e o seu som era imitado pelas demais dentro do tempo de uma frase musical de quatro compassos (Figura 1).

Qual é o som?

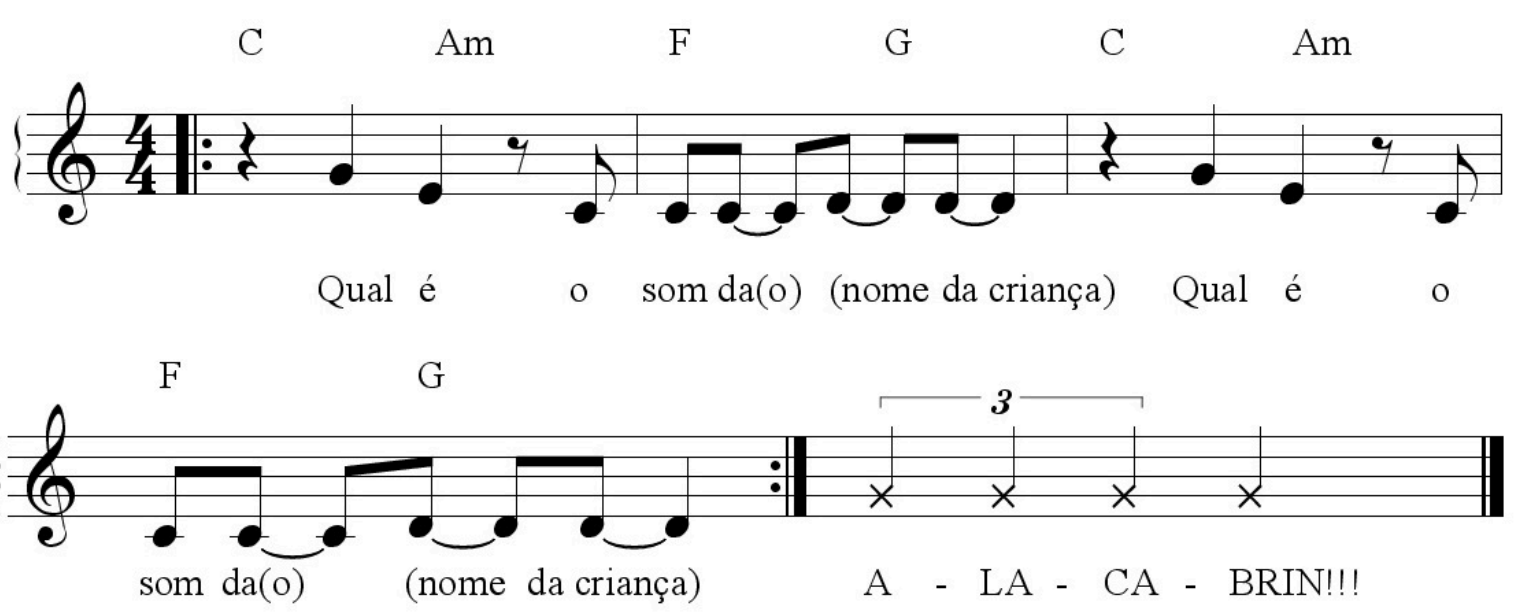

Figura 1: Partitura “Qual é o som?”. Fonte: Elaboração própria.

Ao refletir sobre inventar canções, Britto (2003) fala sobre a interferência do adulto nas atividades. A autora sugere que a criança invente letra e melodia e que o adulto proponha temas, ajude a organizar as ideias e, se necessário, componha "uma melodia para cada criança do grupo: as canções com nomes" (Britto, 2003, p. 135). Surgiu, assim, um pequeno tema com nomes e sons vocais das crianças, como um estímulo e complemento às brincadeiras musicais - de improviso, imitação e descobertas sonoras vocais. As canções com nomes têm grande valor, pois estabelecem um contato afetivo e efetivo entre todos. É importante ressaltar que o pensamento de Brito foi 
um guia para o planejamento, destacando-se a importância da criação realizada pelas crianças sem interferência do adulto, atividade que foi proposta e desenvolvida no semestre seguinte e que não está sendo analisada neste artigo.

A corporeidade está relacionada à concepção fenomenológica de percepção que, em concordância com Merleau-Ponty (1999), o corpo é um campo criador de sentidos. Nas palavras do autor: "ÉE por meu corpo que compreendo o outro, assim como é por meu corpo que percebo "coisas" (Merleau-Ponty, 1999, p. 253). A corporeidade, transposta para a educação infantil, como a percepção do mundo pelos sentidos e comunicados por gestos, ou seja, um corpo como experiência se si mesmo (Merleau-Ponty, 1999), foi trabalhada pelo professor-personagem Teobaldo que, juntamente com as crianças da Tribo do Piolho, criaram movimentos para expressar corporalmente a criação musical por eles desenvolvida.

Os pequenos dançaram individualmente, em duplas e em grupos ao som da canção que foi acompanhada pela harmonia do violão de Teobacia. Parafraseando Merleau-Ponty (1999), os pequenos se experimentaram por meio de seus corpos, que, em sua dimensão funcional, não é apenas um lugar de racionalidade e expressividade, mas também de abertura e criação. Para Maffioletti (2013, p. 131), "Considerar a criança como ponto de partida é propor atividades de som e movimento, de modo que ela vivencie com o corpo aqueles elementos necessários à compreensão musical". Foi dando ao corpo a possibilidade de perceber, pensar, observar, comunicar e agir que as crianças potencializaram a corporeidade aliada aos elementos musicais que, paralelamente, estavam sendo trabalhados.

Plasticidade sonora, plasticidade do movimento, plasticidade neural, teoria matemática da plasticidade. O termo plasticidade tem sua origem etimológica na palavra grega Plastikós associada ao domínio da estética (Leal, 2004). Segundo Leal, a plasticidade evoca "toda uma perspetiva material, mas também conceptual, dominada pela variabilidade e pela transformação, cujo pano de fundo é essa matéria mole de que a mão humana é o agente metamorfoseador" (Leal, 2004, p. 18). Foi na perspectiva da plasticidade sonora e do movimento, usando materiais sujeitos à modelação, à mutabilidade e à modificação, como, por exemplo, cordas e fios, que se desenvolveram algumas atividades com a Tribo do Piolho. Em seu trabalho, Vidor (2010) relaciona plasticidade a objetos como conchas, pedras, entre outros, na posição de elemento simbólico como identificação de determinado grupo.

Após o encontro com Teobacia no bosque da escola, surgiu o professor assumindo o personagem Clodoaldo, o costureiro, e a proposta para construir chocalhos de pés. Lá havia um grande entrelaçado de corda amarrado em duas árvores, simulando uma teia de aranha. Clodoaldo propôs que as crianças criassem um acessório, com fios variados e outros objetos, que pudesse auxiliar a composição da melodia que haviam criado. A ideia de levar 
o chocalho de pé, nos pulsos ou como um colar, partiu do interesse da Tribo do Piolho interligada à brincadeira da teia de aranha. A aprendizagem e a experiência dessas crianças ocorreram por meio de uma relação plástica com o mundo em favor de um maior desenvolvimento sensorial.

\section{BRINCAR: CRIAÇÃO MUSICAL COLETIVA}

Mas um dia, um menino bem menino, que era como são os meninos de todos os tempos, ficou incomodado por não ter tempo para brincar. Invocado como era, convocou as outras crianças para apresentar sua grande ideia: ele queria levantar o céu! (Conto, Ulisses Belleigoli).

O que as crianças poderiam fazer para que o céu não caísse e elas pudessem voltar a brincar? O brincar "cotidianamente de diversas formas, em diferentes espaços e tempos, com diferentes parceiros (crianças e adultos)" é um dos direitos de aprendizagem estabelecido pela Base Nacional Comum Curricular (BNCC, 2017, p. 36). Brincando, a criança "amplia e diversifica o seu acesso a produções culturais, seus conhecimentos, sua imaginação, sua criatividade, suas experiências emocionais, corporais, sensoriais, expressivas, cognitivas, sociais e relacionais" (BNCC, 2017, p. 36).

O lúdico diz respeito às brincadeiras que, frente aos papéis assumidos pelas crianças nesse contexto interativo ou individual, propicia e aciona seus pensamentos para a resolução de problemas. Segundo Brito (2003, p. 35), "a criança é um ser 'brincante' e, brincando, faz música, pois assim se relaciona com o mundo que descobre a cada dia". As palavras da autora foram seguidas à risca durante a prática musical desenvolvida com as crianças, pois o processo de criação coletiva se deu a partir do brincar por meio de diversas atividades lúdicas.

O pó mágico foi relacionado a uma palavra também mágica - Alacabrin - e, assim, iniciou-se a exploração vocal. Outras palavras e outros sons foram experimentados com a boca, língua e bochechas, por meio de brincadeiras e imitações uns dos outros. As crianças imitaram sons de pássaros e outros diversos sons da natureza, ouviram a canção "Puff!", ${ }^{3}$ do compositor Hélio Ziskind, fizeram improvisos vocais e criaram desenhos para os sons e para a palavra mágica, resultando em uma partitura analógica e na gravação em áudio da sequência sonora. Além disso, aliaram movimentos corporais aos sons que agora estavam gravados. Para Brito (2007), música, vida, fantasia e imaginação se cruzam nas repetições do cotidiano. Para a autora "As dúvidas, comentários e descobertas que as diferentes vivências provocam permitem

\footnotetext{
${ }^{3}$ Do CD Trem maluco:

<https://www.youtube.com/watch?v=ZOmFuaDIYxo\&index=19\&list=PLEYtJnI2aqBZsPIDZwcQ5HX_RCpuGUg4>.
} 
que as crianças criem hipóteses, discutam, analisem, tirem conclusões" (p. 124).

Em uma atividade de apreciação com a música "Samba lelê", do grupo Barbatuques, ${ }^{4}$ uma das meninas, encantada com um dos sons produzidos pelos estagiários, relata: "Isso é mágica, porque não precisa fazer som com a boca, só bater a palma perto e sai som". A sonoridade referia-se ao som produzido com as mãos em forma de concha e com os lábios em forma de bico. Ao bater as mãos próximo aos lábios entreabertos são produzidos variados timbres. Foi a descoberta das ondas sonoras que, indiretamente, estava ligada à brincadeira de sonorizar. As crianças menores costumam centrar-se na exploração de gestos e intensidade e, de acordo com Brito (2007), esta pode estar relacionada ao fato de que um repertório de gestos resulta em blocos de sonoridade.

A aparição dos professores personagens - Teobacia, Clodoaldo e Teobaldo - reforçou a criação sonora coletiva. Com seu violão, Teobacia trouxe um novo estímulo para o grupo quando novamente exploraram sonoridades vocais e corporais. De repente, um dos pequenos disse: "Você não é uma criança, é um homem". Esse foi mais um momento em que a situação apresentada flutuou entre a ludicidade e a vida real. Clodoaldo contribuiu com a confecção dos chocalhos de pé e o trabalho com a plasticidade. A parte de furar as tampas de garrafas pet e entrelaçá-las com barbantes foi previamente feita pelos professores. Cada criança escolheu um recorte de tecido e nele amarraram os barbantes que continham as tampas. Depois de prontos, foram amarrados nos tornozelos e punhos das crianças como parte instrumental da criação sonora. Esse trabalho foi baseado nas falas das crianças, em suas percepções sobre música e em suas ideias sobre mundo.

Deslumbrando crianças dançantes, Teobaldo, com sua dança maluca, incentivou as crianças a moverem-se corporalmente. Ao jogar o pó mágico sobre os pés, não tinha mais controle sobre si, era necessário deixar que os pés conduzissem o corpo para a dança. No início essa música era aleatória, dançante, escolhida pelas estagiárias de Teatro, porém, finalizava com a criação sonora dos pequenos da Tribo do Piolho. Observou-se que a cada aula as crianças traziam novas sugestões, interagiam com os professores com uma liberdade propiciada por um ambiente acolhedor. Ao escutar o que as crianças dizem e fazem e ao perceber como elas vivem a música, conforme apontam Brito (2007) e Maffioletti (2013), aprende-se a conhecê-las e amplia-se a visão que se tem sobre elas e sobre o modo com que leem a realidade.

Valorizar as ideias musicais torna as crianças seguras para produzir e refletir sobre música, e foi dessa forma que a criação sonora foi desenvolvida. Dentre as várias atividades planejadas, buscou-se alternativas e estratégias que oferecessem estruturas para uma criação coletiva e liberdade para a

\footnotetext{
${ }^{4}$ Do CD Tum Pá: <https://www.youtube.com/watch?v=_Tz7KROhuAw>.
} 
participação individual e em grupo. Pensando na educação infantil, Horn e Fabris (2018, p. 543), ressaltam que é necessário investir em "um sujeito infantil autônomo, livre, responsável pela sua própria educação, empreendedor e inovador". As autoras acreditam que a criança de zero a cinco anos pode ser estimulada a fazer suas próprias escolhas, passando assim a investir em seus interesses e, consequentemente, empreender sua própria aprendizagem.

As práticas musicais na educação infantil são fruto de estudos sobre a criança e a infância que contribuíram para compreender que a música pode "assumir seu lugar e importância na formação da criança como ser humano" (Maffioletti, 2013, p. 130). Ter a criança como personagem principal implica conhecer os seus contextos, cultural e social, seus interesses e preferências, considerar seus conhecimentos prévios e poder transformar os processos de ensino e aprendizagem em "uma espécie de jogo, característico dessa fase de desenvolvimento humano, por meio do qual a criança possa aprender brincando" (Maffioletti, 2013, p. 131). Dessa forma, acredita-se que é possivel um ensino de música que considere a escolha das crianças, suas expressões, ambições e do que lhe é intrínseco, assim como ser um professor mediador que observa e valoriza suas ideias.

\section{ESTÁGIO, EDUCAÇÃO INFANTIL E INTERDISCIPLINARIDADE}

Realizar o estágio curricular supervisionado em música com uma turma de educação infantil e com uma proposta interdisciplinar foi um desafio triplo. Primeiro, o estágio por si só, como um componente de formação docente, exige o exercício da profissão em um campo de trabalho, por vezes, diferente daquele que o licenciando está familiarizado. Essa experiência prática, além de proporcionar o desenvolvimento de habilidades necessárias ao desempenho da ação docente, coloca o licenciando em contato com um contexto profissional determinado, com características sociais, culturais e educacionais próprias. O estagiário, em pouco tempo, precisa conhecer a escola, os alunos, os professores e os demais funcionários da instituição, bem como observar, planejar e atuar em sala de aula. É uma imersão, sem dúvida, desafiadora.

Segundo, se por um lado pouco se estuda sobre música na infância nos cursos de Licenciatura em Música, por outro, experiências com projetos interdisciplinares são praticamente inexistentes. De maneira geral, há pouco espaço nas disciplinas da graduação dedicado aos estudos da criança pequena em relação à música. Essa constatação pode ser confirmada tanto pelos programas curriculares quanto pelo número de licenciandos que escolhem a educação infantil como campo de estágio. No primeiro semestre de 2017, dos 40 estudantes matriculados na disciplina de Estágio Curricular Supervisionado I e III do curso de Licenciatura em Música da Universidade do Estado de Santa Catarina (UDESC), apenas dois optaram pela educação infantil. Essa realidade foi confirmada por Mateiro (2011) em cursos de outras 
instituições e remete à baixa procura dos estudantes e/ou à pouca oferta dos professores formadores para esse campo de trabalho.

Ao conhecer a história da legislação brasileira, é possível compreender que tanto a educação infantil quanto os primeiros anos do ensino fundamental não têm sido contemplados com as disciplinas de música, artes visuais, teatro ou dança (ver Penna, 2008). Essas e outras disciplinas nesses níveis de ensino costumam ficar a cargo do professor generalista. Dessa forma, os cursos de Licenciatura em Música dão maior ênfase a conhecimentos e práticas musicais voltados para crianças maiores, e os respectivos campos de estágio acabam por ser aqueles onde há a presença de um professor de música, ou seja, na maioria das vezes, em escolas públicas, em turmas de ensino fundamental II e no ensino médio. Normalmente, é em escolas particulares que há aulas de música para crianças pequenas com professores especialistas, ${ }^{5}$ como foi confirmado, por exemplo, na pesquisa realizada, em Brasília, por Marques (2011).

É sabido que as crianças não fazem distinção entre o trabalhar música e, em seguida, teatro, pois a aprendizagem de maneira integrada faz parte do contexto da educação infantil. Para elas, os elementos são abordados em conjunto, como na fala de uma das crianças: "Vamos fazer um teatro musical". Entretanto, os processos formativos que iniciam na educação básica e chegam à universidade, de acordo com Zitkoski (2014, p. 59), "decorrem de um modelo de educação fragmentador da visão de mundo e voltado, sobretudo, para atingir resultados imediatos". Essa formação está em crise, pois "a ciência produzida segundo os cânones da lógica disciplinar foi padecendo de um excesso de certezas, da arrogância acadêmica e da falta de diálogo entre as diferentes áreas e, também, da ausência de diálogo entre as ciências e os demais saberes (popular, filosófico, místico etc.)" (Zitkoski, 2014, p. 59-60).

O estágio foi proposto como uma ação interdisciplinar entre licenciandos de Música e Teatro. De acordo com Raynaut (2014, p. 185), a primeira etapa do percurso de aprendizagem da interdisciplinaridade, além de consistir em desenvolver "um olhar crítico sobre a produção do conhecimento em geral e sobre sua própria disciplina em particular", deverá "criar as condições iniciais de um diálogo entre especialidades científicas distintas". O diálogo foi, assim, o pano de fundo para o planejamento das aulas que foram pensadas em conjunto entre professores e estudantes, bem como com as ideias das crianças, principalmente da Tribo do Piolho.

Essa reflexão coletiva permitiu um novo modo de cooperar e interagir com outras formas de pensar, abordar e se adaptar a novas situações pedagógicas. Atitudes semelhantes também foram observadas em estudantes de música e teatro de outras turmas que, durante três anos, participaram do

${ }^{5}$ Consultar revisão de literatura (Egg, 2016). 
projeto interdisciplinar de estágio desenvolvido na UDESC (Mateiro, 2014). A troca, o diálogo, as experiências práticas, o se colocar no lugar do outro, a incerteza da ação, as negociações, as decisões conjuntas e as diferentes vivências teatrais e musicais permearam as aulas das disciplinas de estágio curricular supervisionado, estimulando, assim, estágios interdisciplinares.

As rodas de conversas estiveram presentes em todas as aulas, sendo que, no decorrer das atividades, as crianças partilhavam suas ideias sobre a proposta e como buscar alternativas para resolver as situações, tanto musicais quanto aos demais desafios que a elas foram propostos. Desse modo, a resolução do problema lançada aos pequenos da Tribo do Piolho foi alcançada por meio de uma abordagem integrada, pois foi possivel cruzar e articular musicalidade, movimento, expressão corporal, plasticidade e confecção de figurinos para uma estória sonorizada, criada pelas crianças. Tudo isso abriu um leque de possibilidades interdisciplinares, não apenas pelo significado do valor da música na infância, mas para desenvolver atividades com cantos e sons de diversas culturas, suas crenças, danças e expressões.

\section{PORTFÓLIO DIGITAL}

O material produzido durante o período de estágio foi organizado em um portfólio digital tendo como referência o conceito de portfólio educacional. Para Carvalho e Porto (2005), o portfólio educacional apresenta-se como uma coleção de trabalhos dos professores em formação que descreve seus esforços, progressos e conquistas em uma determinada área. Além disso, é uma combinação entre processo e produto, é um meio de refletir sobre diferentes contextos, é o registro de metas e dos atributos profissionais desenvolvidos ao longo do tempo. Em resumo, é uma produção intelectual que mostra o professor como um sujeito reflexivo e construtor de suas ações em sala de aula, de forma sucinta e substantiva.

Durante a graduação, o portfólio educacional é construído para dar suporte à aprendizagem. Serafim e Celino (2014) compartilham a ideia de ser uma coleção das produções dos estudantes que sinalizam as construções de suas aprendizagens. Foi nesse sentido que os estudantes do curso de Licenciatura em Música (ver também Gonçalves; Costa, 2014), estagiária e bolsista de iniciação científica selecionaram vários documentos que evidenciaram sua prática pedagógica. Destacam-se: um resumo e um link para a leitura completa do projeto de estágio; pequenos trechos de vídeos das atividades realizadas com as crianças; áudio da criação coletiva e fotos com pequenos relatos de transições entre os três elementos que fizeram parte da metodologia: musicalidade, plasticidade e corporeidade.

A plataforma utilizada foi o site gratuito Wix, que permite que os usuários criem sites em HTML5 e sites Mobile, isto é, adaptáveis para dispositivos móveis. Dentre as ferramentas que a plataforma oferece, há uma lista na 
lateral esquerda que possibilita a inclusão de conteúdo, desde a edição do menu, com várias possibilidades de cores, imagens, caixas de textos em diversos formatos, armazenamento de uploads, até a criação de seu próprio blog. Possibilita ao usuário manter o sigilo de seu material ou publicá-lo online, adicionar ou criar páginas para membros por meio de login, podendo o administrador gerenciá-las.

O primeiro momento de elaboração do portfólio exigiu estudo e adaptação às ferramentas editoras do website, além de uma disponibilidade maior de tempo para a edição. A limitação do site na criação de uma conta para dois usuários foi outra dificuldade, pois ambos não tinham acesso simultaneamente ao conteúdo. Após essa fase, seguiu-se a organização do portfólio como estratégia de desenvolvimento de uma postura profissional, onde os estudantes em formação docente são responsáveis por sua própria educação, instigando o espírito crítico e autônomo (Carvalho; Porto, 2005).

Tomar decisões conjuntas sobre a seleção do material e desenvolver a habilidade de compartilhar e permitir o trabalho em equipe, visando um projeto educativo democrático, conforme Carvalho e Porto ressaltam, exigiu discussão e reflexão. O que selecionar? Por que esse material e não outro? Dessa forma, a organização do portfólio seguiu o formato da ênfase na prática reflexiva como aquele que inclui: documentos sobre a pré-prática, como projeto de estágio, com referencial teórico e atividades pedagógico-musicais; documentos sobre a prática, como planos de aula e registro de atividades, e documentos sobre a pós-prática, como o relatório final de estágio, com reflexões e autoavaliação.

\section{CONSIDERAÇÕES FINAIS}

Nem a antiga língua da grande tribo tem palavras para descrever o encantamento daquela manhã. O céu foi subindo, subindo, subindo, até colar lá no infinito. E as árvores se espreguiçaram, e os pássaros se alvoroçaram pelos ares! E os adultos desencurvaram-se e animaram-se para o trabalho, para a vida, para a liberdade que haviam ganhado de presente (Conto, Ulisses Belleigoli).

A educação infantil é um contexto possivel de trabalho para os futuros professores de música. Entretanto, realizar o estágio curricular supervisionado com crianças pequenas não tem sido uma escolha frequente dos licenciandos. Muitas razões podem justificar a realização do estágio em outras faixas etárias, desde a própria estrutura curricular do curso de Licenciatura em Música, com a oferta ou não de disciplinas e conteúdos voltados para o estudo da infância, até os campos disponíveis para o estágio, que, de acordo com a legislação, não prevê o professor de música nesse nível de ensino. Nesse caso, se, por um lado, raramente se encontra um professor de música que atue na educação infantil e que possa ser o professor supervisor de estágio, por outro, é necessário buscar instituições que aceitem 
licenciandos dos cursos de música que possam trabalhar em parceria com os professores pedagogos. O NDI da UFSC, nesse sentido, tem sido uma instituição acolhedora e participativa na formação de futuros professores, não só de Música e Teatro, como também de outras áreas.

A criança ocupou o centro do processo educativo e seus interesses funcionaram como estratégias para o protagonismo infantil. Reflexões foram compartilhadas com os pequenos da Tribo do Piolho por meio de discussões e diálogos sobre as atividades realizadas. O escutar possibilitou traçar novas estratégias, considerando as conquistas, os limites e as dificuldades enfrentadas ao longo do período de estágio. Assim, alcançou-se um resultado significativo no desenvolvimento musical e cognitivo das crianças, embora este não tenha sido o principal objetivo deste trabalho.

A ideia do portfólio digital exigiu diversas habilidades, capacidades e competências. A seleção do material foi o primeiro passo para a reflexão sobre a ação pedagógica dos estudantes em formação. Entretanto, o fato de o portfólio ter sido elaborado em conjunto fez com que não adquirisse características mais individuais e profissionais de cada um dos estudantes. A discussão sobre a diferença entre o portfólio em papel e o portfólio digital também esteve presente em boa parte do tempo em que os licenciandos liam artigos e livros a respeito. Por fim, foi possivel perceber que seria necessário mais tempo para que pudessem se apropriar do portfólio como uma estratégia de ensino e aprendizagem que pode: motivar o estudante a refletir sobre sua formação; proporcionar o desenvolvimento de habilidades coletivas; promover a capacidade de resolução de problemas; estruturar as prioridades e tarefas de aprendizagem; e fornecer informações necessárias para transformar os conteúdos compreensiveis às necessidades dos alunos.

O trabalho integrado exigiu dedicação, diálogo e cooperação de toda a equipe. A cada aula ficava mais visivel e possivel a intencionalidade de trabalhar o interdisciplinar em relação às atividades propostas. A criação sonora vocal foi o disparador e identificador da Tribo do Piolho. O aprender brincando foi uma estratégia presente nas aulas que uniu elementos integrados ao fazer musical, como: brincar de teatro, brincar de experimentar sons diversos, contar histórias, cantar, dançar, sonorizar e criar. A utilização da metodologia do drama auxiliou o desenvolvimento do processo, uma vez que era necessária a pesquisa semanal por situações significativas de aprendizagem. A construção da narrativa, a busca por soluções, a atuação dos professores-personagem, as informações reais vividas por meio da ficção, bem como a reflexão sobre as atividades interdisciplinares proporcionaram, tanto para as crianças quanto para os estudantes em formação docente, experiências desafiadoras que aliaram elementos da musicalidade, da plasticidade e da corporeidade.

A aproximação dos estudantes de música em formação docente à realidade da criança pequena, que aprende, descobre e interage, exigiu o desenvolvimento de um conjunto de habilidades cognitivas e a capacidade de 
trabalhar cooperativamente em equipe. Os estagiários aprofundaram e vivenciaram conceitos como situação-problema, drama, musicalidade, plasticidade, corporeidade, criança brincante, criação musical coletiva, interdisciplinaridade e portfólio digital. Desse modo, o estágio se constituiu como um momento de integração entre teoria e prática, bem como um processo criador, de investigação e intervenção na realidade, favorecendo o desenvolvimento da identidade profissional. Os estagiários se apropriaram da realidade da escola e, especialmente, da educação infantil. Esse conjunto de vivências contribuiu significativamente para o desenvolvimento reflexivo e autoformativo do estudante em formação docente.

No último dia de aulas, as quatro turmas compartilharam suas soluções em uma grande reunião que se chamou ensinamentos. Uma sala temática foi preparada com uma lona azul com altura baixa e um emaranhado de fios, simulando o céu baixo da Tribo Tchanan. A Tribo Vagalume abriu o portal com o professor-personagem Feiticeira e com a palavra mágica "Abranuvens!". A Tribo das Estrelas, com o professor-personagem Ratiki, ensinou como falar com os animais e como se movimentar num lugar tão baixo e sem muito espaço. A Tribo do Piolho, com o professor-personagem Teobacia, cantou sua criação musical para alegrar o céu. Por fim, a Tribo Guerreiros Filhos de Urucum, com seu professor-personagem Teobaldo, convidou todas as tribos para dançar, pois o céu finalmente voltou ao seu lugar.

Agradecimentos. Às crianças, à coordenação e à professora do NDI. Às professoras Camila Zanetta e Melissa Ferreira pela orientação dos estágios. Ao Alessandro Shiquefuzi, à Amalia Leal e à Emeli Barossi pela parceria. Às professoras Heloise Vidor e Lígia Mara Santos pela leitura e sugestões.

\section{REFERENCIAS}

BRASIL. Conselho Nacional de Educação/Câmara de Educação Básica. Resolução $n^{\circ}$ 5, de 17 de dezembro de 2009. Fixa as Diretrizes Curriculares Nacionais para a Educação Infantil. Brasília: Ministério de Educação, 2009.

BRASIL, Base Nacional Comum Curricular. Brasília: Ministério de Educação, 2017.

BRITO, Teca Alencar de. Música na Educação Infantil: propostas para a formação da criança. 2. ed. São Paulo: Peirópolis, 2003.

BRITO, Teca Alencar de. Por uma educação musical do pensamento: novas estratégias de comunicação. 2007. Tese (Doutorado em Comunicação e Semiótica) - Pontifícia Universidade Católica de São Paulo, São Paulo, 2007.

CABRAL, Beatriz Ângela Vieira. Drama como método de ensino. São Paulo: Mandacaru, 2006. 
CARVALHO, Marie Jane Soares; PORTO, Leonardo Sartori. Portfólio

Educacional: Proposta Alternativa de Avaliação/Guia Didático. Porto Alegre: Editora da UFRGS, 2005.

EGG, Marisleusa de Souza. A prática pedagógica de um professor na educação infantil: um estudo sobre as atividades cantadas na aula de música. 2016. Dissertação (Mestrado em Música) - Universidade do Estado de Santa Catarina, Florianópolis, 2016.

GONÇALVES, Lilia Neves; COSTA, Maria Cristina Souza. O portfólio como uma proposta de documentação, registro e avaliação na prática de ensino em música. In:

HORN, Cláudia Inês; FABRIS, Eli Terezinha Henn. Documentação pedagógica na educação infantil: Tecnologia de governamento da infância contemporânea. Educação Temática Digital (ETD), Campinas, v. 20, n. 2 p. 539-554, 2018.

LEAL, Miguel. A plasticidade: cartografias sonoras. In: RAMOS, Maria (coord. e ed.). Pedro Tudela. Porto: Fundação de Serralves, 2004, p. 18-41. Disponivel em:

<https://webcache.googleusercontent.com/search?q=cache:dpI55kvabEJ:https://sigarra.up.pt/fbaup/pt/pub_geral.show_file\%3Fpi_gdoc_id\%3D1 $9971+\& c d=1 \& h l=p t-P T \& c t=c l n k \& g l=b r>$. Acessado em: 30 mar. 2018.

MAFFIOLETTI, Leda de Albuquerque. Significações que possibilitam a compreensão musical. In: BROOCK, Angelita; ILARI, Beatriz (Org.). Música e educação infantil. Campinas: Papirus, 2013. p. 123-145.

MARQUES, Mônica Luchese. A ação pedagógico-musical na Educação Infantil: um estudo de caso com uma professora de música. Dissertação (Mestrado em Música) - Universidade de Brasília, Brasília, 2011.

MATEIRO, Teresa. Dinâmicas Interdisciplinares com Música e Teatro na Formação de Professores. In: GAUTHIER, Fernando Ostuni et al. (Orgs.). INTERdisciplinaridade: teoria e prática. Florianópolis: UFSC/EGC, 2014. p. 145-166.

MATEIRO, Teresa. A formação profissional para a educação musical infantil: algumas considerações. In: SANTIAGO, Diana; BROOCK, Angelita; CARVALHO, Tiago (Orgs.). Educação Musical Infantil. Salvador: PPGMUS UFBA, 2011.

MERLEAU-PONTY, Maurice. Fenomenologia da percepção. Trad. Carlos Alberto Ribeiro de Moura. 2. ed. São Paulo: Martins Fontes, 1999.

PENNA, Maura. Música(s) e seu Ensino. Porto Alegre: Sulina, 2008.

RAYNAUT, Claude. Os desafios contemporâneos da produção do conhecimento: o apelo para interdisciplinaridade. In: GAUTHIER, Fernando et al. INTERdisciplinaridade: teoria e prática. Vol. I. Florianópolis:

UFSC/EGC, 2014. p. 169-189. 
SERAFIM, Maria Lúcia; CELINO, Marta Lúcia de Souza. O portfólio digital como tecnologia no processo de avaliação. In: CONGRESSO IBEROAMERICANO DE CIÊNCIAS, TECNOLOGIA, INOVAÇÃO E EDUCAÇÃO, 2014, Buenos Aires. Anais... Buenos Aires: OEI, 2014. p.1- 15. Disponivel em: <https://www.oei.es/historico/congreso2014/memorias2014.php>. Acessado em: 30 mar. 2018.

TEIXEIRA, Sônia Regina dos Santos. A construção de significados nas brincadeiras de faz-de-conta por crianças de uma turma de educação infantil ribeirinha da Amazônia. 2005. Tese (Doutorado em Teoria e Pesquisa do Comportamento) - Instituto de Filosofia e Ciências Humanas, Universidade Federal do Pará, Belém, 2005.

VIDOR, Heloise Baurich. Drama e teatralidade. Porto Alegre: Mediação, 2010.

ZITKOSKI, Jaime José. A interdisciplinaridade na formação universitária: desafios contemporâneos. In: GAUTHIER, Fernando et al.

INTERdisciplinaridade: teoria e prática. Vol. II. Florianópolis: UFSC/EGC, 2014. p. 57-77.

Teresa Mateiro é Professora Associada do Departamento de Música da Universidade do Estado de Santa Catarina (UDESC). Atua nos Programas de Pós-Graduação, Mestrado em Música (PPGMUS) e Mestrado Profissional em Artes (PROF-ARTES) na mesma instituição. Tem Licenciatura e Mestrado em Educação Musical pela Universidade Federal do Rio Grande do Sul (UFRGS) e Doutorado em Educação - Educação Musical pela Universidade do País Vasco, Espanha. Realizou Pós-Doutorado na Universidade de Lund, Suécia. É líder do Grupo de Pesquisa Educação Musical e Formação Docente (UDESC/CNPq). É editora da Revista ORFEU (PPGMUS/UDESC) e da Revista Nupeart (CEART/UDESC) e membro do Conselho Editorial da Revista Internacional de Educación Musical (ISME) e da Revista DAPEsquisa (CEART/UDESC). Desenvolve pesquisas na área de Formação Docente privilegiando temas como prática pedagógica, programas curriculares, conhecimento profissional, práticas musicais escolares e estudos transculturais em educação musical.

Silani Pedrollo possui graduação em Pedagogia pela Universidade Paranaense (2001). Atua na área de Artes, com ênfase em Música. Formada em teclado eletrônico em 1996. Atuou como professora de teclado eletrônico, canto e flauta na Escola Artemúsica de 1994 a 2010. Participou como vocal de gravações do CD Nosso Rock, com a banda paranaense DXavantes. Foi integrante de grupos vocais e bandas, como ArteMúsica, Quarteto Nossa Voz e banda Auto Retrato e Orquestra de Violão de Toledo. Participou de festivais de música como intérprete (1992/1995) e juradas (2008/2010). Desde 2011 mora em Florianópolis, onde trabalha como professora particular de violão, teclado, flauta e canto; como professora de musicalização em escolas de educação infantil. Trabalhou como oficineira de canto e violão pela Fundação Flanklin Cascaes (2012). Atualmente é Licencianda do curso de Música da UDESC com bolsa de Iniciação Científica PROBIC/UDESC. 